\title{
Engenharia Didática: características e seus usos em trabalhos apresentados no GT-19 / ANPEd 1
}

\author{
Saddo Ag Almouloud \\ saddoag@pucsp.br \\ Programa de Estudos Pós-graduados em Educação Matemática - PUC/SP \\ Cileda de Queiroz e Silva Coutinho \\ cileda@ pucsp.br \\ Programa de Estudos Pós-graduados em Educação Matemática - PUC/SP
}

Resumo: $\mathrm{O}$ artigo tece algumas reflexões sobre pesquisas fundamentadas nos princípios da Engenharia Didática. Num primeiro momento, discutem-se os fundamentos $\mathrm{e}$ as características desta metodologia de pesquisa, e, à luz desses fundamentos, é proposta uma reflexão sobre os trabalhos apresentados no GT-19 (Educação Matemática) da ANPEd (Associação Nacional de Pós-Graduação e Pesquisa em Educação) de 1999 a 2005 que se utilizam da Engenharia Didática ou de seus pressupostos.

Palavras-Chave: Engenharia Didática, Educação Matemática, Metodologia de Pesquisa.

Abstract: The article develops some thinking on researches based on Didactic Engineering principles. At a first moment, the discussion covers fundaments and characteristics of this research methodology and, under these fundaments, a discussion is proposed on the papers presented at GT-19 (Mathematical Education) by ANPEd, from 1999 to 2005, which use Didactic Engineering or its pre-supposed concepts.

Key-Words: Didactic Engineering, Mathematical Education, Research methodology

\footnotetext{
1 GT-19/ANPEd: Grupo de trabalho 19 da Associação Nacional de Pós-Graduação e Pesquisa em Educação (Brasil) 


\section{Introdução}

As pesquisas em Educação Matemática têm se desenvolvido segundo metodologias diversas, em abordagens quantitativas ou qualitativas. Entre as qualitativas, vários esforços podem ser percebidos na construção de seqüências didáticas e materiais didáticos em ambientes específicos, computacionais ou não, visando seja o estudo de sua aplicabilidade como o diagnóstico de concepções, dificuldades, obstáculos, níveis de desenvolvimento do raciocínio envolvido, entre outros.

Neste texto analisaremos algumas pesquisas cuja abordagem apóia-se nos princípios da Engenharia Didática (ARTIGUE, 1988). Discutiremos seus fundamentos, e caracterizando as pesquisas apresentadas no GT-19 (Educação Matemática) da ANPEd, desde 1999, que os usam como metodologia de pesquisa. Serão objetos de nosso estudo os objetivos, as questões, as hipóteses, os fundamentos teóricos e metodológicos da pesquisa, bem como os principais resultados alcançados.

Começaremos esse texto pela explicitação do que entendemos por pesquisa, questão e hipóteses de pesquisa, para em seguida discutirmos os pressupostos da Engenharia Didática vista como metodologia de pesquisa, para finalmente analisarmos os trabalhos apresentados no grupo de trabalho citado.

\section{I - Definindo alguns conceitos}

Concordamos com CHIZZOTTI (1991) quando afirma que o processo de pesquisa é um conjunto de operações sucessivas e distintas, mas interdependentes, realizadas por um ou mais pesquisadores, a fim de coletar sistematicamente informações válidas sobre um fenômeno observável para explicá-lo ou compreendê-lo. É um trabalho complexo que desenvolve a organização pessoal, além de reunir diferentes competências, tais como escrever, sistematizar, analisar, e domínio de técnicas especializadas como documentação, instrumentos de pesquisas, etc. (ibid, p.35).

As pesquisas em Didática da Matemática (escola francesa) são geralmente de tipo experimental que submetem o fenômeno à experimentação e a uma intervenção a partir da organização sistemática dos fenômenos observados. Para Chizzotti (1991)

A experimentação significa que se recorre à experiência, ou seja, os fatos e acontecimentos são apreendidos em um contexto de normas constantes e, por isso, podem ser sistematicamente observados, deliberadamente organizados e sujeitos a uma 
intervenção planificada para permitir inferências e previsões sobre os fatos que se dêem nas mesmas condições. (p.26).

Para discutirmos o que entendemos por problema de pesquisa, recorremos à Lakatos e Marconi (1991), para quem este é o assunto que se deseja provar ou desenvolver, "uma dificuldade ainda sem solução, que é mister determinar com precisão, para intentar, em seguida, seu exame, avaliação crítica e solução" (ASTI VERA (1976), apud LAKATOS e MARCONI, 1991). Segundo os autores, a formulação de um problema prende-se ao tema proposto e indica exatamente qual a dificuldade que se pretende resolver. Formular um problema consiste em dizer, de maneira explícita, clara, compreensível e operacional, qual a dificuldade com a qual nos defrontamos e que pretendemos resolver, limitando o seu campo e apresentando suas características. Desta forma, o objetivo da formulação do problema da pesquisa é torná-lo individualizado, específico, inconfundível. Segundo Robert (1992):

as pesquisas [...] em Didática da Matemática são freqüentemente articuladas em torno de uma questão que nos colocamos sobre uma aprendizagem ou sobre um problema de ensino, ou ainda sobre uma hipótese que procuramos confirmar (particularmente a existência de uma regularidade entre um certo tipo de ensino e um certo tipo de aprendizagem para uma maioria de alunos). (Ibid, p. 38, tradução nossa).

Para nós, a problemática de uma pesquisa é o conjunto de questões coordenadas que se colocam num determinado quadro teórico para esclarecer o problema colocado e os objetivos do estudo. Ela introduz a metodologia da pesquisa e apresenta as conclusões esperadas sob forma de questões abertas (hipóteses) induzidas pelo quadro teórico escolhido. Ainda segundo Robert (1992):

trata-se de inscrever o questionamento em um conjunto teórico mais amplo, coerente, no qual as noções utilizadas têm uma conotação precisa, e ao mesmo tempo, passar das questões mais ou menos gerais para questões ou hipóteses acessíveis em uma pesquisa no quadro de referência escolhido.(Ibid, p. 38-39, tradução nossa)

Dessa forma, o objetivo da pesquisa é confirmar ou refutar contribuições teóricas a partir de uma argumentação que se apóia em uma experimentação. A problemática reenvia aos artigos e obras atestados ou trabalhos que tratam do assunto em um processo de validaçãorefutação, propondo as etapas da pesquisa e da experimentação, além de definir como esse plano corresponde aos objetivos devidamente fixados e explicitados. 
Quanto à hipótese de pesquisa, concordamos com Lakatos e Marconi (1991) quando definem que a hipótese de uma pesquisa é um enunciado geral de relações entre variáveis (fatos, fenômenos):

- formulado como solução provisória para um determinado problema;

- apresentando caráter ou explicativo ou preditivo;

- compatível com o conhecimento científico (coerência externa) e revelando consistência lógica (coerência interna);

- sendo passível de verificação empírica em suas conseqüências.(Ibid, p.125)

De um ponto de vista mais global, voltando a discutir o que entendemos por pesquisa, mas já dentro do que se entende por problemática, destacamos que uma das características de uma estratégia de pesquisa em Educação Matemática (escola francesa) é o duplo movimento de teorização e de provas experimentais. Nesse processo é importante buscar respostas as seguintes indagações:

- O que é variável?

- O que se considera como fixo?

- O que se estuda e qual tipo de resultado se quer obter com os meios que se tem à disposição?

- Onde se situa o assunto abordado no conjunto de sistema do ensino?

- Quais são as variáveis potenciais?

A identificação das variáveis potenciais pode minimamente garantir certa generalidade das explicações dos fenômenos observados (ou seja, as explicações resultantes das análises feitas pela transformação de fatos observados em fenômenos didáticos).

Se as variáveis didáticas potenciais não são cuidadosamente identificadas, nada garante a generalidade das explicações dos fatos observados e dos efeitos do artefato utilizado que acontecem independentemente do controle do experimentador. (ROBERT, 1992, p. 40, tradução nossa)

Enfim, é no quadro da problemática definida acima que interpretamos os resultados obtidos, porque escolhemos as variáveis (as dimensões, os fatores que têm influência sobre o que estamos estudando), o ponto de vista e a participação da realidade.

\section{II- Engenharia Didática: uma metodologia de pesquisa}

A noção de Engenharia Didática emergiu na Didática da Matemática (enfoque da didática francesa) no início dos anos 80. Segundo Artigue (1988), é uma forma de trabalho didático comparável ao trabalho do engenheiro que, para realizar um projeto, se apóia em conhecimentos científicos de seu domínio, aceita se submeter a um controle de tipo científico, 
mas ao mesmo tempo, é obrigado a trabalhar objetos mais complexos que os objetos depurados da ciência.

A Engenharia Didática, vista como metodologia de pesquisa, caracteriza-se, em primeiro lugar, por um esquema experimental baseado em "realizações didáticas" em sala de aula, isto é, na concepção, realização, observação e análise de sessões de ensino. Caracterizase também como pesquisa experimental pelo registro em que se situa e modo de validação que lhe são associados: a comparação entre análise a priori e análise a posteriori ${ }^{2}$. Tal tipo de validação é uma das singularidades dessa metodologia, por ser feita internamente, sem a necessidade de aplicação de um pré-teste ou de um pós-teste.

A Engenharia Didática pode ser utilizada em pesquisas que estudam os processos de ensino e aprendizagem de um dado conceito e, em particular, a elaboração de gêneses artificiais para um dado conceito. Esse tipo de pesquisa difere daquelas que são transversais aos conteúdos, mesmo que seu suporte seja o ensino de certo objeto matemático (um saber ou um saber-fazer).

\section{As diferentes fases da metodologia da Engenharia Didática}

\section{1) As análises prévias}

Em uma pesquisa cuja metodologia é fundamentada nos pressupostos da Engenharia Didática podemos identificar algumas fases de seu desenvolvimento, que tomam como base um quadro teórico geral da didática. A primeira fase é aquela na qual se realizam as análises preliminares, que pode comportar as seguintes vertentes:

- epistemológica dos conteúdos visados pelo ensino;

- do ensino usual e seus efeitos;

- das concepções dos alunos, das dificuldades e dos obstáculos que marcam sua evolução;

- das condições e fatores de que depende a construção didática efetiva;

- a consideração dos objetivos específicos da pesquisa;

- o estudo da transposição didática do saber considerando o sistema educativo no qual insere-se o trabalho.

Segundo Artigue (1988), cada uma dessas fases é retomada e aprofundada ao longo do trabalho de pesquisa, em função das necessidades emergentes. Isso significa que a expressão "análises preliminares" não implica que após o início da fase seguinte não se possa retomálas, visto que a temporalidade identificada pelo termo "preliminar" ou "prévia" é relativa, pois 
se refere apenas a um primeiro nível de organização. Na realidade, deve ser um trabalho concomitante com as demais fases da pesquisa. Estas análises preliminares devem permitir ao pesquisador a identificação das variáveis didáticas potenciais que serão explicitadas e manipuladas nas fases que se seguem: a análise a priori e construção da seqüência de ensino.

\section{2) Construção e análise a priori}

Artigue (1988) distingue dois tipos de variáveis potenciais que serão manipuladas pelo pesquisador:

- as variáveis macrodidáticas ou globais relativas à organização global da engenharia

$\mathrm{e}$

- as variáveis microdidáticas ou locais relativas à organização local da engenharia, isto é, a organização de uma sessão ou de uma fase.

Esses dois tipos de variáveis podem ser de ordem geral ou dependente do conteúdo matemático estudado e suas análises serão realizadas em três dimensões: a dimensão epistemológica (associada às características do saber), a dimensão cognitiva (associada às dimensões cognitivas dos alunos sujeitos da aprendizagem) e dimensão didática (associada às características do sistema de ensino, no qual os sujeitos estão inseridos).

O objetivo de uma análise a priori é determinar como as escolhas efetuadas (as variáveis que queremos assumir como pertinentes) permitem controlar os comportamentos dos alunos e explicar seu sentido. Dessa forma, em uma análise a priori devemos:

- Descrever as escolhas das variáveis locais e as características da situação adidática desenvolvida.

- Analisar a importância dessa situação para o aluno e, em particular, em função das possibilidades de ações e escolhas para construção de estratégias, tomadas de decisões, controle e validação que o aluno terá. As ações do aluno são vistas no funcionamento quase isolado do professor, que, sendo o mediador no processo, organiza a situação de aprendizagem de forma a tornar o aluno responsável por sua aprendizagem;

- Prever comportamentos possíveis e tentar mostrar como a análise feita permite controlar seu sentido, assegurando que os comportamentos esperados, se e quando eles intervêm, resultam do desenvolvimento do conhecimento visado pela aprendizagem.

\section{3) Experimentação, análise a posteriori e validação.}

A fase da experimentação é clássica: é o momento de se colocar em funcionamento todo o dispositivo construído, corrigindo-o se necessário, quando as análises locais do desenvolvimento experimental identificam essa necessidade, o que implica em um retorno à

\footnotetext{
${ }^{2}$ Detalharemos mais adiante as especificidades de uma análise a priori e de uma análise a posteriori
} 
análise a priori, em um processo de complementação. Ela é seguida de uma fase de análise a posteriori que se apóia no conjunto de dados recolhidos durante a experimentação: observações realizadas sobre as sessões de ensino e as produções dos alunos em sala de aula ou fora dela. Esses dados são, às vezes, completados por dados obtidos pela utilização de metodologias externas: questionários, entrevistas individuais ou em pequenos grupos, realizadas em diversos momentos do ensino.

A análise a posteriori de uma sessão é o conjunto de resultados que se pode tirar da exploração dos dados recolhidos e que contribuem para melhoria dos conhecimentos didáticos que se têm sobre as condições da transmissão do saber em jogo. Ela não é a crônica da classe, mas uma análise feita à luz da análise a priori, dos fundamentos teóricos, das hipóteses e da problemática da pesquisa, supondo que:

- $\quad$ a observação foi preparada por uma análise a priori conhecida do observador.

- $\quad$ os objetivos da observação foram delimitados por ferramentas apropriadas, e estruturados também pela análise a priori.

Assim, a análise a posteriori depende das ferramentas técnicas (material didático, vídeo) ou teóricas (teoria das situações, contrato didático...) utilizadas com as quais se coletam os dados que permitirão a construção dos protocolos de pesquisa. Esses protocolos serão analisados profundamente pelo pesquisador e as informações daí resultantes serão confrontadas com a análise a priori realizada. O objetivo é relacionar as observações com os objetivos definidos a priori e estimar a reprodutibilidade e a regularidade dos fenômenos didáticos identificados.

\section{III - Mapeamento dos trabalhos apresentados}

Nesta parte do artigo mapeamos as pesquisas que utilizam, de modo explicito (ou implícito), a Engenharia Didática como metodologia de pesquisa ou de seus os pressupostos. Delas buscamos destacar os objetivos, as questões, as hipóteses, os fundamentos teóricos e metodológicos, bem como os principais resultados alcançados. O quadro a seguir contém a lista dos trabalhos que foram analisados e seus autores, bem como o ano de publicação: 


\begin{tabular}{|l|l|c|}
\hline \multicolumn{1}{|c|}{ AUTOR(ES) } & \multicolumn{1}{|c|}{ TITULO DO TRABALHO } & ANO DE PUBLICAÇÃO \\
\hline $\begin{array}{l}\text { Abraão Juvênicio de Araújo, } \\
\text { Verônica Gitirana - UFPE }\end{array}$ & $\begin{array}{l}\text { A construção do conceito de } \\
\text { simetria rotacional através de um } \\
\text { ambiente no Cabri-géomètre: } \\
\text { análise de uma sequêencia } \\
\text { didática. }\end{array}$ & 2000 \\
\hline $\begin{array}{l}\text { Paula Moreira Baltar Bellemain, } \\
\text { Paulo Figueredo Lima - UFPE }\end{array}$ & $\begin{array}{l}\text { Análises previas à concepção de } \\
\text { uma engenharia de formação } \\
\text { continuada para professores de } \\
\text { Matemática do Ensino } \\
\text { Fundamental do demonstração }\end{array}$ & 2000 \\
\hline $\begin{array}{l}\text { Saddo Ag Almouloud, Elizabeth } \\
\text { Gervazoni Silva e Mello - PUC- } \\
\text { SP }\end{array}$ & $\begin{array}{l}\text { Iniciação à } \\
\text { aprendendo conceitos } \\
\text { geométricos }\end{array}$ \\
\hline $\begin{array}{l}\text { Cileda de Queiroz e Silva } \\
\text { Coutinho - PUC-SP }\end{array}$ & $\begin{array}{l}\text { Probabilidade Geométrica: Um } \\
\text { contexto para a modelização a a } \\
\text { simulação de situações aleatórias } \\
\text { com Cabri }\end{array}$ & 2000 \\
\hline $\begin{array}{l}\text { Irene Pataki, Saddo Ag } \\
\text { Almouloud - PUC/SP }\end{array}$ & $\begin{array}{l}\text { Equador, paralelos e meridianos: } \\
\text { apenas linhas imaginárias }\end{array}$ & 2002 \\
\hline
\end{tabular}

\section{Análise dos trabalhos apresentados na reunião anual de 2000}

Encontramos três trabalhos cujos fundamentos metodológicos baseiam-se na Engenharia Didática.

\section{A construção do conceito de simetria rotacional através de um ambiente no Cabri-} géomètre: análise de uma seqüência didática. (Araújo \& Gitirana - UFPE)

O trabalho de Araújo e Gitirana tem por objetivo apresentar e analisar didaticamente uma seqüência de ensino para a construção do conceito de simetria rotacional, elaboradas num ambiente computacional com o software Cabri-géomètre, para alunos de $6^{\mathrm{a}}$ série. O estudo prévio constou:

- do estudo do objeto matemático,

- de um estudo sobre o ensino/aprendizagem do objeto matemático que permitiu aos autores identificar alguns dos fatores que interferem no processo ensino/aprendizagem do conceito de simetria rotacional. Além disso, consideraram as variáveis constitutivas do saber utilizadas por Hart (1982), procurando controlar a relação entre o número de partes correspondentes que compõe a figura e o ângulo de rotação.

- do estudo das características que permitem utilizar o computador como uma ferramenta auxiliar para investigar como se dá a aquisição de conceitos geométricos. Os autores optaram pela utilização do ambiente Cabri-géomètre por acreditar que ele promove processos de aprendizagem específicos e por possibilitar a criação de 
situações que proporcionam modos de ação e de validação, quando os alunos interagem com a máquina durante a resolução de situações-problema.

A metodologia de pesquisa utilizada, segundo os autores, foi a Engenharia Didática cujos princípios foram brevemente descritos no trabalho.

A seqüência didática construída e sua análise a priori mostraram o objetivo de criar condições que permitissem aos alunos perceber:

- $\quad$ a relação entre o número de partes correspondentes que compõe a figura e o ângulo de rotação;

- $\quad$ a igualdade de distâncias de pontos correspondentes ao centro de rotação;

- $\quad$ o ângulo que se forma entre os segmentos, que ligam o centro de rotação a dois pontos correspondentes consecutivos, tem a mesma medida do ângulo de rotação.

De nosso ponto de vista, o texto apresentado discute uma pesquisa que tomou como base metodológica alguns dos princípios da Engenharia Didática, embora não identifique claramente as variáveis didáticas (macro e/ou microdidáticas) cuja escolha interfere de modo positivo nos comportamentos dos alunos em situação de aprendizagem. Tal explicitação, que seria parte da análise a priori construída, não está presente no texto. No aspecto da validação, a interlocução entre a análise a priori, os objetivos da pesquisa e a análise a posteriori, considerando as variáveis didáticas, os fundamentos teóricos e o ambiente computacional está apenas implícita pelo anúncio de que a metodologia segue os pressupostos da Engenharia Didática, não aparecendo efetivamente no presente artigo. Encontramos referência a essa interlocução no texto quando os autores apresentam a análise dos resultados, porém não aparece aqui suficientemente explorada para caracterização da validação interna da engenharia.

\section{Análises prévias à concepção de uma engenharia de formação continuada para} professores de Matemática do Ensino Fundamental. Bellemain \& Lima - UFPE

O objetivo do trabalho de Bellemain e Lima foi investigar a concepção de uma Engenharia visando a formação de professores. Os autores destacam a pluralidade de saberes que devem ser articulados em um processo de formação, tais como o cultural, o matemático, o psico-pedagógico, o didático e o profissional, e que devem ser articulados pelo formando e colocados em prática na situação de sala de aula. Graças a essa pluralidade, os autores entendem que não é possível fazer uma analogia direta entre esta Engenharia e a Engenharia 
Didática de formação embora uma metodologia próxima àquela proposta por Artigue (1988) possa ser seguida.

São apresentados resultados que fazem parte da fase de "análises prévias", nas quais procuraram abordar alguns dos diferentes tipos de saber em jogo no processo de formação do professor de matemática.

O domínio Matemático escolhido é o das grandezas geométricas e suas medidas, em especial, o conceito de área. Constam dos estudos prévios:

- o estudo do objeto matemático "grandezas e medidas" no sistema de ensino atual;

- o estudo do objeto matemático "conceito de área" e o processo de medir área do ponto de vista da estrutura matemática subjacente;

- $\quad$ a apresentação de alguns resultados de avaliação e de pesquisas sobre o ensinoaprendizagem dos conceitos de área e perímetro, que mostram a variedade, a profundidade e a resistência de algumas dificuldades conceituais na construção desses conceitos;

- $\quad$ uma discussão sobre as representações de professores de matemática do Ensino Fundamental e Médio;

- uma discussão final da fase "análises prévias", registrando a contradição entre as representações dos professores do baixo grau de dificuldade conceitual atribuída pelos alunos aos conteúdos de área e perímetro e os resultados das pesquisas sobre o ensino e aprendizagem destes mesmos conteúdos levando os autores a conjeturarem algumas interpretações possíveis.

Completando as análises prévias, Bellemain e Lima apresentam um estudo de várias pesquisas sobre o tema "representação dos professores sobre a Matemática e o seu ensino", no qual buscam destacar os itens relativos a Grandezas e Medidas. À luz dessas análises os autores levantaram um conjunto de questões, que podem ser objetos de pesquisa, cujos resultados poderão fornecer elementos teórico-metodológicos para investigações mais amplas a respeito da formação de professores de matemática e anunciam a continuação da pesquisa aqui apresentada.

\section{Iniciação à demonstração: aprendendo conceitos geométricos. Almouloud \& Mello -} PUC-SP

O texto apresentado por Almouloud e Mello indica que a pesquisa faz parte de um projeto maior que estuda os fenômenos de ensino e aprendizagem de conceitos geométricos, elaborado a partir da constatação da dificuldade que os alunos enfrentam para compreender esses conceitos. Um de seus objetivos foi de provocar uma reflexão sobre os problemas de formação de conceitos geométricos nos alunos, bem como sobre a formação de professores 
dos $3^{\circ}$ e $4^{\circ}$ ciclos da Escola Básica para o ensino de geometria. No quadro da problemática desta pesquisa, os autores indicam ainda o objetivo de investigar o problema da demonstração, buscando alternativas e respostas para os desafios colocados ao ensino de Geometria nessa fase de escolaridade. Uma das preocupações da pesquisa é buscar respostas para a seguinte questão: Quais fatores exercem mais influência no ensino e no desenvolvimento de habilidades geométricas no que diz respeito à demonstração?

Os estudos feitos sobre o ensino-aprendizagem da demonstração e os estudos preliminares realizados mostraram as dificuldades que os alunos encontram na aquisição de conceitos geométricos. Um dos problemas que encaminham ao fraco desempenho de alguns alunos, no que diz respeito aos conceitos e habilidades geométricas, ocorre devido à prática $\mathrm{e}$ às escolhas didáticas dos professores quando ensinam Geometria.

Os alunos de quinta a oitava séries do Ensino Fundamental não parecem beneficiar-se de um ensino que lhes proporcione condições para:

- compreender a mudança do estatuto da figura (objeto, representação), os estatutos da definição e dos teoremas geométricos, das hipóteses (dados do problema) e conclusão (ou tese);

- saber utilizar as mudanças de registros de representações;

- apropriar-se do raciocínio lógico-dedutivo.

Para minimizar esses problemas, os autores apontam a necessidade de construir situações de ensino-aprendizagem, que contemplem os seguintes aspectos:

- figuras geométricas que tenham um papel heurístico e levem em conta suas diferentes apreensões: perceptiva, discursiva, operatória e seqüencial;

- demonstração, como parte integrante do processo de ensino e aprendizagem, dos conceitos/habilidades geométricas e do raciocínio lógico-dedutivo;

- a importância dos registros de representação (desenho/figura geométrica, linguagem natural, linguagem matemática).

Os autores consideram o estudo da demonstração uma ferramenta eficaz para a compreensão de conceitos geométricos e para a aquisição de algumas habilidades em Geometria, apoiando-se na teoria de registros de representação semiótica de Duval (1995) e nas seguintes hipóteses:

1- O processo de aquisição dos conhecimentos, em particular, dos conhecimentos em Geometria, considera os seguintes aspectos:

- observação de provas associadas a tomadas de decisão;

- a atividade de resolução de problemas geométricos; 
- atividade de formulação;

- entendimento e redação da solução de problemas.

2- A resolução de problemas de Geometria e a entrada na forma de raciocínio, que essa resolução exige, está associada à distinção das apreensões da figura (apreensão seqüencial, perceptiva, discursiva e operatória).

3- As representações semióticas não são somente necessárias para fins de comunicação, mas também essenciais para as atividades cognitivas do pensamento. A atividade exigida em Geometria, no Ensino Fundamental, mobilizar três registros e sua coordenação: o registro da língua natural, o registro das figuras e o registro matemático (ou das escritas algébricas).

4- A construção de situações para a sala de aula, nas quais a iniciação à demonstração tem um papel importante, conduz alunos de $5^{\mathrm{a}}$ a $8^{\mathrm{a}}$ série a uma melhor compreensão dos conceitos geométricos e à aquisição de habilidades geométricas.

5- A técnica da demonstração está mais associada a uma hierarquia de tarefas do que a uma hierarquia de conteúdos.

Considerando as dificuldades levantadas por Duval (1995), entre outros, e pelos dados obtidos nos estudos preliminares, os autores desenvolveram uma sequiência didática (parte da Engenharia Didática elaborada) para validar suas hipóteses, tendo em vista os aspectos teóricos e os processos que favorecem a construção dos conceitos geométricos. As situações construídas consideram ainda a significação da demonstração que, de acordo com Balacheff (1987, 188) distingue explicação, prova e demonstração. A análise a posteriori, indicada pelos autores, mostra que as atividades se desenvolveram, no decorrer do desenvolvimento da seqüência didática, em um processo de aprendizagem por meio de discussões, distinção entre definição e propriedade, associação dos registros de representação e estabelecimento de um conceito por uma definição ou uma propriedade geométrica. $O$ texto evidencia também o processo de validação interna da engenharia. Os autores se depararam com algumas dificuldades relacionadas á administração das atividades desenvolvidas e aos processos de aquisição de certos conhecimentos. Uma delas é a coordenação de todos os subproblemas envolvidos em uma determinada tarefa que os levou à necessidade de desenvolver outras atividades com o objetivo de propiciar aos alunos a organização de esquemas de demonstração e a coordenação de diferentes registros de representação semiótica ligados ao tratamento dos conhecimentos em jogo.

\section{Análise dos trabalhos de 2002}

Encontramos apenas um trabalho cuja metodologia de pesquisa se configura como sendo uma Engenharia Didática ou pelo menos, seguindo os princípios dessa metodologia explicitamente. 
Probabilidade Geométrica: Um contexto para a modelização e a simulação de situações aleatórias com Cabri. Coutinho - PUC-SP

O texto apresentado mostra um recorte do trabalho de tese da autora (Coutinho, 2001) que trata de um estudo sobre a introdução ao conceito de probabilidade para alunos do Ensino Fundamental, procurando trabalhar com a familiarização com situações aleatórias em ambiente escolar. A autora faz a hipótese de que os alunos já convivem com a aleatoriedade e têm contato com vários tipos de geradores de acaso em sua vida extra-escolar. O objetivo do artigo é discutir essa introdução em ambiente escolar por meio de um contexto de probabilidade geométrica que propõe aos alunos a identificação do modelo que melhor representa o jogo de "Franc-Carreau". A autora se propõe ainda a discutir uma seqüência didática cujo objetivo é familiarizar o aluno com situações aleatórias por um ponto de vista experimental, visando assim um processo de ensino e aprendizagem por meio de situaçõesproblema que envolvem a modelagem de experimentos simples.

Pode-se identificar no texto, embora não de forma explícita, as análises preliminares feitas para a elaboração da engenharia didática que é proposta pela autora. Tal análise aparece no texto de forma articulada com a análise a priori da situação proposta, o jogo do "Franc Carreau", e descreve as etapas do jogo com suas implicações didáticas e as variáveis que foram utilizadas na construção das atividades e na organização da engenharia. A análise preliminar mostra um estudo didático e matemático do conceito de probabilidade, enquanto a análise a priori evidencia as etapas da atividade e o estudo do ambiente computacional utilizado, o Cabri-géomètre II, indicando as vantagens do trabalho com a probabilidade geométrica e com este software como ferramenta para simulação da experiência aleatória que representava o jogo proposto.

A validação da engenharia pode ser identificada na conclusão do texto, na qual a autora faz a articulação entre os estudos preliminares e análise a priori com as constatações feitas na análise a posteriori (que não foi apresentada no texto).

\section{Análise dos trabalhos de 2004}

Encontramos só um trabalho cuja metodologia de pesquisa se configura como sendo uma Engenharia Didática ou pelo menos, seguindo os princípios dessa metodologia. 
Equador, paralelos e meridianos: apenas linhas imaginárias. Pataki \& Almouloud PUC/SP

O trabalho de Pataki e Almouloud tem por objetivo propor uma reflexão acerca da articulação entre a Geometria esférica e a Geografia apresentando os principais resultados de uma sequiência didática, elaborada a partir de uma situação-problema, que visou mostrar a relação entre esses domínios do conhecimento.

A proposta desenvolveu-se em diversas fases (segundo os princípios da Engenharia Didática) nas quais, primeiramente, os autores procuraram analisar o ponto de vista filosófico gerador de uma posição unicista do pensamento matemático - a filosofia de Kant - e as implicações no progresso desse pensamento; consultaram os Parâmetros Curriculares Nacionais do Ensino Fundamental e do Ensino Médio, a respeito do ensino de Matemática, em especial de Geometria, e sobre o recurso da interdisciplinaridade; realizaram ainda estudos a respeito do ensino, por meio de publicações em torno da Geometria riemanniana ou esférica e exploraram as concepções de professores acerca dessa Geometria do ponto de vista da teoria e da prática pedagógica.

Alicerçados pelos estudos preliminares, os autores apontaram as seguintes hipóteses de pesquisa:

- $\mathrm{O}$ conhecimento geométrico possibilita a compreensão/ descrição/representação de forma organizada do nosso mundo.

- A apreensão dos conteúdos constituintes da Geometria esférica poderá nos conduzir a argüições/reflexões/transformações/conscientização da nossa posição como docente, diante da ação pedagógica.

- A utilização dos recursos da interdisciplinaridade e da contextualização promoverá conexões/encadeamentos/solidez de saberes inerentes à Geometria esférica e de outros campos de conhecimento.

A elaboração e a experimentação da seqüência de ensino contendo uma situaçãoproblema e mais oito atividades fundamentaram-se na Teoria das Situações Didáticas (Brousseau, 1986), que permeia o processo de ensino e aprendizagem com situações de ação, de formulação, de validação e da institucionalização do conhecimento. Uma das finalidades das situações desenvolvidas é fazer emergir outras geometrias e, portanto conhecimentos novos que permitam solucionar problemas que a geometria euclidiana não consegue, colocando à disposição dos docentes envolvidos na formação bolas de isopor de diferentes diâmetros, um globo terrestre grande e vários globos pequenos. 
As realizações didáticas foram direcionadas pela metodologia de pesquisa intitulada Engenharia Didática que possibilitou o controle desse processo, por se basear na concepção, na realização, na observação e na análise (a priori e a posteriori) da situação-problema e de cada uma das atividades. $\mathrm{Na}$ fase da análise a priori, os autores fizeram previsões sobre os possíveis métodos/estratégias de resolução de cada situação e os conhecimentos mobilizados em cada uma; identificaram as possíveis dificuldades que podem surgir na resolução de cada situação e os novos conhecimentos/saberes que poderão ser adquiridos e institucionalizados.

A análise a posteriori apoiou-se nos dados obtidos na experimentação, por meio de observações, das produções dos professores e das discussões ocorridas durante os encontros cuja confrontação possibilitou a validação das hipóteses de pesquisa.

Os autores perceberam algumas mudanças de atitudes e valores, por parte dos professores envolvidos no projeto, no momento da troca de experiências individuais, porque para solucionar o problema precisaram integrar-se às discussões, deliberando suas conclusões com mais segurança e determinação. A contextualização da situação proposta permitiu que diversos conhecimentos fossem utilizados para resolvê-la, inter-relacionando saberes de Matemática e de Geografia.

Os resultados alcançados permitiram aos autores inferir que a seqüência de ensino proposta, a partir de uma situação-problema, parece consistente e coerente, porque sua construção, tal como o trabalho de engenheiro, apoiou-se em alicerces firmes previamente estabelecidos e edificou-se por meio da relação entre teoria e experimentação e finalizou-se com sua validação e institucionalização.

\section{Conclusão}

Observamos que os trabalhos apresentados tinham um objetivo comum: o estudo do processo de ensino e aprendizagem de um dado conceito e a construção de uma seqüência didática com o intuito de proporcionar ao aluno condições favoráveis à construção e compreensão desse conceito. A elaboração, a análise e a experimentação das situaçõesproblema propostas são geralmente precedidas por estudos prévios, como preconizado pelos princípios da Engenharia Didática. No entanto, percebemos que as escolhas das variáveis potenciais nem sempre foram explicitadas e analisadas considerando os resultados das outras fases dessa metodologia. As análises dessas variáveis, quando feitas, não explicitam de modo claro as três dimensões exigidas pelos pressupostos de uma Engenharia Didática, a saber: a epistemológica, a cognitiva e a didática. 
A análise a posteriori das seqüências didáticas - exceto o trabalho de Bellemain \& Lima que tomou como base os estudos preliminares - aparece de forma articulada (para a maioria dos trabalhos) com a análise a priori, os fundamentos teóricos e as hipóteses das pesquisas. Indícios de validação da Engenharia Didática podem ser identificados nas conclusões dos textos analisados, mas não percebemos de modo nítido a estimativa de reprodutibilidade e de regularidade dos fenômenos didáticos identificados.

As pesquisas analisadas são, em geral, recortes de trabalhos mais amplos (dissertações de mestrado, doutorado ou resultados de projeto em andamento) que adaptados às exigências da ANPEd, em termos de formatação geral e condições para proposta de trabalhos, levaram os autores a algumas escolhas para a produção de seus textos. Essas escolhas, na maioria dos casos, não permitiram provavelmente apresentar todas as fases da Engenharia Didática desenvolvida, privilegiando o tratamento mais profundo de algumas fases, enquanto outras aparecem, muitas vezes, de maneira implícita. Acreditamos assim que tais fatores podem ser uma justificativa para as limitações que apontamos nos trabalhos analisados.

\section{REFERÊNCIAS}

ARTIGUE, M. (1988): "Ingénierie Didactique". Recherches en Didactique des Mathématiques. Grenoble: La Pensée Sauvage-Éditions, v. 9.3, 281-308.

ARTIGUE, M. (1990). Epistémologie et Didactique. Recherches en Didactique des Mathématiques. Grenoble: La Pensée Sauvage-Éditions, v. 10 n 2.3, p.241-286.

ASTI VERA, A.(1976): Metodologia da pesquisa cientifica. Porto Alegre: Globo.

CHIZZOTTI A. (1991): Pesquisas em ciências humanas e sociais. $3^{a}$ ed. São paulo: Cortez Editora.

DOUADY, R. (1993): L'ingénierie didactique: un moyen pour l'enseignant d'organiser les rapports entre l'enseignement et l'apprentissage. Cahier de DIDIREM, Paris: IREM de Paris VII.

DUVAL R. (1988): "Approche cognitive des problèmes de géométrie". Annales de Didactiques et de sciences cognitives, Strabourg: IREM de Strarsbourg v.1, p.57-74.

DUVAL R. (1995). Sémiosis et pensée humaine: registres sémiotiques et apprentissages intellectuels. Peter Lang.

LAKATOS, E. M., Marconi, M. de A. (1991). Metodologia científica, ciência e conhecimento, métodos científicos, teoria, hipóteses e variáveis. Atlas, $2^{\mathrm{a}}$ Edição revista e ampliada.

ROBERT, A. (1992): "Problèmes méthodologiques en Didactique des Mathématiques". Recherches en Didactique des Mathématiques. Grenoble: La Pensée Sauvage-Éditions, v.12.1, p.33-58.

SILVA DE MELLO, E., G. (1999). Demonstração: uma seqüência didática para a introdução de seu aprendizado no ensino da Geometria. Dissertação de Mestrado em Educação Matemática, PUC-SP. 